\title{
Study on Characteristics of Japanese Culture and Sino-Japanese Cross-cultural Communication
}

\author{
Xiaojiao Li
}

School of Foreign Studies, Xi'an University, 710065

Keywords: Japanese culture; Characteristics; Cross-cultural communication; Study

\begin{abstract}
In this article, starting from the Japanese deep cultural consciousness, an in-depth analysis of the characteristics of Japanese culture was performed. Moreover, the conflicts during the Sino-Japanese cross-cultural communication and causes of such conflicts were interpreted, and finally suggestions on how to make cross-cultural communication better were proposed.
\end{abstract}

\section{Introduction}

Sino-Japanese conflict has a long history; the existence of such a conflict leads to a lot of contradictions in the process of Sino-Japanese cross-cultural communication. After the in-depth studies by Chinese scholars, it is found that the main reason for these contradictions is the huge difference in the values, thinking patterns and behavior patterns between the two countries. In order to further promote the process of cross-cultural communication between the two countries, we must firstly carry out a profound interpretation on the Japanese culture, thus we can abandon the prejudice in the process of communication, giving full respect and understanding to the Japanese culture. As the saying goes, "if you know your enemies and know yourself, you will not be imperiled in a hundred battles".

\section{Contents of Study on Sino-Japanese Cross-cultural Communication}

\section{Japanese Deep Cultural Consciousness}

Group Consciousness

As we all know that the Japanese people are very united, because they believe in the Japanese groupism. Group consciousness can be regarded as the most significant national character of the Japanese people, which should be attributed to the Japanese hereditary rice planting culture. Japan is an island country, and the land resources, arable land and mineral resources are very scarce. Under such a living environment, the Japanese developed a habit of mutual help and mutual understanding, forming a family-like affectional tie between people. This kind of consciousness not only exists in daily life, but also has a very significant embodiment in the work. The leaders in the higher positions on the one hand set the harsh work objectives for their subordinates, but on the other hand they fully consider for the sake of the subordinates. They even use some excellent benefits to reward subordinates after work. Because of the existence of such a tie, the Japanese people form a value orientation of loyalty and emphasis on friendship.

Internal-external Distinction

The internal-external distinction refers to the antiforeign attitude of Japanese in dealing with people from other countries. This is mainly because Japan is a nation-state, keeping a vigilance over foreigners. Japanese enterprises uniformly implement life-long employment system postwar, that is, a person only serves for a company throughout his/her life. At the same time, the promotion mechanism within the Japanese enterprises mainly use the seniority-based wage system, which further strengthens the internal-external distinction in Japanese consciousness.

Although the Japanese have maintained a very strong vigilance over the foreigners, they are in favor of a variety of cultures from other countries. The Japanese are very happy to learn and absorb the excellent culture and technology of other countries. Through continuous learning of the excellent culture and advanced technology and self-improvement, Japanese society was able to develop continuously and rapidly.

Shame Culture 
Shame culture is the definition for the Japanese culture type given by the American anthropologist Ruth Benedict after analysis of a large number of data. In fact, shame culture is also an important part of traditional Chinese culture. Shame, is the collective internal control force outside the law, which invisibly controls people's values and ideas. The famous Japanese "Bushido" spirit is also a reflection of the shame culture. If lose the battle, the Japanese warriors would prefer to commit suicide instead of dragging out an ignoble existence. The shame culture also results in the Japanese characteristics of being concerned about face and reputation. For the face-saving, the Japanese developed a tactful philosophy of life.

Religious Consciousness

Japan is a country where religion is extremely common. According to relevant statistics, nearly $80 \%$ of Japanese set kamidana to offer sacrifices to Gods and Buddha, niche for a statue of the Buddha and altar in their homes. There are $50 \%$ and even nearly $80 \%$ of Japanese people usually keep the ritual of offering sacrifices to Gods and Buddha. Moreover, many people are doing a variety of things to seek help from the God and Buddha for the health and security of their family, elimination of ill fortune, booming business, passing the exam and happy marriage etc.

\section{Conflict of Sino-Japanese Cross-cultural Communication}

Different Values. The values are defined as the perception, understanding, judgment or choice based on a certain thinking and sense of human, that is, the thinking orientation for people to identify things, and distinguish between right and wrong, thus reflecting the value and role of people, things and objects. In other words, the values dominate the way of people in handling affairs, and also reflect the degree of civilization of a country.

For Japanese, work is the absolute center. A large number of Japanese devote all their lives to their company. In Japan, the aged often would not choose to retire after reaching the retirement age, but continue to serve the enterprise, because once they stop working, they would lose the goal of struggle, and the life becomes meaningless. In Japanese enterprises, it is very common that the leaders give corporal punishment, scold and slap the subordinates, because the Japanese believe that if they do not complete the task well, they are disloyal to their enterprise and should be subjected to such punishment.

However, for Chinese people, the family is the only center; all the behaviors are family-oriented, which is the result of inheritance of traditional Confucianism "marry and settle down". Therefore, there is a huge difference in the values of collectivism between China and Japan, and this difference further leads to the conflict of Sino-Japanese cross-cultural communication.

Different Patterns of Behavior. The difference in patterns of behavior is also an important factor of the conflict in Sino-Japanese cross-cultural communication. In Japan, because of the influence of "Bushido" culture, the Japanese people become very sensitive and extremely demand perfection of their behaviors. Therefore, they pay much attention to the face, for fear of making some inappropriate behaviors and lost face. In addition, the Japanese society also has very strict norms on people's behavior. People who spit and litter will be subjected to punishment, and even moral condemnation. Therefore, in the eyes of Chinese people, Japanese are very rigid; they are usually neat and orderly, comply with discipline, have a strong sense of time, but silent. It is precisely because of these features, the Japanese form the characteristics of being rigorous. In some negotiations, the Japanese think carefully, and never compromise, and maintain a very high workplace literacy and strong ability to work as well. On the other hand, the pressure from all sides plus the character of being silent and concerned about face-saving, the Japanese cannot get rid of stress, but bear it by themselves. This has resulted in a very high suicide rate in Japan. They do not think that dying is the manifestation of weakness, but a respectable courage.

On the contrary, in the eyes of the Japanese, the Chinese people are very casual, regardless of organization or discipline, not punctual, do not care for public health, and have no sense of shame. In addition, the Chinese and the Japanese attitudes towards life and death are very different.

Different Patterns of Thinking. Differences in thinking patterns will lead to many obstacles in the Sino-Japanese cross-cultural communication. For example, the Japanese are used to do all the 
things perfectly without any loopholes. The Japanese can be very patient to complete the very boring tasks from beginning to end. However, many Chinese people often cannot be so meticulous or maintain the patience for a long time, and will not pursue perfection.

In dealing with some business problems, the Japanese will argue for their own interest without any compromise and loopholes. Moreover, they will carefully read each word of the contract or agreement. On the contrary, the Chinese people do not like to hold the tit for tat attitude towards their opponents; they prefer to muddle along in some details, as long as the outcome is satisfactory.

\section{Causes of Conflict in Cross-cultural communication}

Over Expectation. In the process of communication between the two countries, if any of them hold very high expectations towards the other, ultimately the results are far below their expectations, and their needs cannot be met, it will further intensify into contradictions.

First of all, there are great differences in social etiquette between China and Japan. During interpersonal communication, Chinese people once form a very close relationship, the body contact will become very intimate, and the behaviors such as patting on the shoulder or laying hand on shoulder among acquaintances are common. However, for the Japanese, such behaviors are very offensive, even if the relationship is close, a certain etiquette must be followed.

Secondly, there are differences in the sense of time between China and Japan. If both sides cannot have a thorough understanding on the sense of time each other in the process of communication, it is easy to cause conflict.

In addition, because the Japanese pursue perfection, and pay attention to face-saving, they are very tactful in dealing with some knotty matters of principle; however, the Chinese people will be very straightforward in dealing with the se problems.

Cognitive Misunderstanding. The cognitive misunderstanding can be considered as a mind-set to an extent, that is, people make judgment on some things based on their cognition, and this judgment is of a strong subjectivity. For example, many Japanese people think that China is poor and backward, and Chinese people are ignorant. However, it was only what their fathers saw many years ago, not today's China. Another example is that many people would like to use their own experience to judge, but such judgment is often very one-sided.

Cognitive Bias. Cognitive bias is the major obstacle to cross-cultural communication between the two countries. For example, since the Sino-Japanese War, the Japanese are very brutal in the eyes of Chinese people. Hence while being in contact with the Japanese, the Chinese people always keep resentful and alert at the beginning. This is the Chinese people's prejudice against the Japanese. However, in fact, there are many friendly Japanese people. Many Japanese perceive that China is poor and backward, and Chinese people are ignorant, so they do not want to do business with China.

However, this biased perception is based on one-sided cognition and fragmented information, which will amplify each other's shortcomings and further aggravate the barriers to communication.

Differences in Social Pursuits. China and Japan are in different social stages; China is a developing country, whereas Japan has been ranked among the developed countries. Therefore, the social pursuits and development goals of the two countries are different. For the Japanese people, the material needs have been met, and now most of them pursue the spiritual fulfillment and the realization of personal values. However, for the Chinese people, the gap between rich and poor is large, and most people still pursue the material satisfaction. In addition, due to the high level of development in Japan, the Japanese people enjoy a very good social welfare, and the happiness index of people's life is higher. While in China, the social welfare is still relatively backward and needs to be improved, and the happiness index of people's life is relatively lower.

\section{Effective Measures to Deal With Such Conflicts}

Make Judgment on Others Objectively and Fairly. We should abandon the prejudice to judge other people, and evaluate others with an objective attitude. In order to objectively evaluate others, the most fundamental way is to deeply understand their social culture, way of thinking and behavior, 
social development level and the overall performance of the society. The behavior of an individual cannot represent the behavior of a group, and a specific event in a specific historical period cannot fully represent a nation's style in handling the matters. Therefore, we must objectively evaluate the Japanese people based on a certain social background, combining with the performance of the whole country without bias.

Overcome the Cognitive Misunderstanding. We should completely remove the empirical cognition which is already formed in our mind to overcome the cognitive misunderstanding. We cannot judge others or things according to our age and experience, etc. Our perception of things is limited to the information we obtain, which is part of the fact but not the entire fact.

Give Each Other a Full Understanding. In the process of cross-cultural communication, there may be some specific behaviors that make each other feel uncomfortable, such as the Japanese stereotypes, silence, and strict requirement for details. At this point we should do what we have to do; we should be punctual, pay the attention to the details, and fully understand their needs, rather than being disgusted. If the Japanese do not compromise in the negotiations, we should adhere to our own principles and, at the same time, give them a reasonable explanation to avoid misunderstanding which may result in further contradictions.

Fully Understand the Cultural Differences. Each country will have its own unique culture because of the limitation of the geographical conditions, natural environment and other factors, and there is a clear difference in the culture between countries. Fully understanding the differences in cultures between the two countries is the basis for cross-cultural communication. During the crosscultural communication, we should maintain the attitude of seeking common ground while reserving differences, adhere to our own culture, and at the same time fully respect other's culture. For example, in dealing with sensitive issues such as the Diaoyu Islands issue, both China and Japan people should keep calm, do not release some extreme remarks or make some radical behaviors. We should recognize the existence of the problem, and find ways together to solve the problem.

\section{Conclusion}

To sum up, the differences in deep cultural consciousness between the Chinese and Japanese people have led to the obstacles of cross-cultural communication between the two countries. In order to better promote the communication between the two countries, both sides should conduct a thorough study on each other's culture, to achieve communication in the business, literature and other aspects on the basis of full respecting each other's culture.

\section{References}

[1] Zhu XW,Zeng Y. Cultural Factors in Japanese Teaching - From the Perspective of Intercultural Communication [J].Journal of Hunan Agricultural University,2007,06:103-105.

[2] Cao DH. The Understanding of Chinese and Japanese Language and Culture in the MacroBackground - Comment on Lu Qinghe 's "Sino-Japanese Communication Culture Comparison" [J].Journal of Bijie University,1998,02:46-47.

[3] Miao LY,Wang HH. A Brief Analysis of the Commercial Communication Characteristics among Japanese People_focus on "the daily greetings" in Japanese commercial communication [J]. Journal of Fuqing Branch of Fujian Normal University,2010,04:71-77.

[4] Weng LX. "Spatial Consideration" and "Cultural Differences" in the Cultural Exchanges between China and Japan: A Case Study of the Translation of Scenic Spots [J]. Journal of Yunnan Nationalities University (Social Sciences Edition),2010,05:108-111.

[5] Wang L. Thinking on Japanese Teaching and Improving Students' Cultural Quality [J]. Journal of Southwest University for Nationalities (Humanities and Social Science Edition),2010,S1:8486. 
[6] Hu HL. On the Revelation of Zhou Zuoren's Study of Japanese Culture in Understanding both Chinese and Japanese Cultures [J]. Journal of Hainan Normal University(Humanities and Social Sciences),2010,05:55-60.

[7] Liu ZR. On the Language Psychology of Japanese from the Comparison of Japanese and Chinese Expressions [J].Journal of Japanese Language Study and Research,2005,04:56-61.

[8] Yang JS. The Development of the Writings about the Japanese [J]. Japanese Studies,2005,01:125-131+134-139.

[9] Chen YJ,Ma FS. The Similarities and Differences of Chinese and Japanese in Different Cultural Backgrounds [J]. Journal of Language and Literature,2014,03:15-16.

[10] Deng RY. On the Introduction of Japanese Culture in Tourism Japanese Teaching [J]. Journal of Taiyuan Urban Vocational College,2012,01:49-50.

[11] Cao ML. Pragmatic Failure in Cross - cultural Communication between China and Japan and Its Countermeasures [J].Periodical Agency of Yangtze University,2012,03:84-85+192.

[12] Jin XM. A Study on the Differences of Consciousness between China and Japan from Social Address Terms [J]. Yunnan Finance \& Economics University Journal of Economics \& Management,2011,05:149-150. 